\title{
La Gran Hidráulica en los ríos Yaqui y Mayo, Sonora, 1936-1957
}

\section{The Great Hydraulics in the Yaqui and Mayo Rivers, Sonora, 1936-1957}

\author{
Gustavo Lorenzana Durán \\ ORCID iD: http://orcid.org/0000-0001-5057-6831 \\ Universidad de Sonora
}

En el trabajo se aborda el papel de la Comisión Nacional de Irrigación y de la Secretaria de Recursos Hidráulicos como constructora la primera y después, como contratistas y supervisoras en la construcción de las grandes presas de almacenamiento sobre el río Yaqui, La Angostura y Álvaro Obregón (Oviáchic) y el río Mayo, Adolfo Ruiz Cortines (Mocúzari), en el estado de Sonora, México, para uso agrícola en los valles del Yaqui y Mayo. También se estudia su incidencia en la modificación del medioambiente.

Palabras clave: Obras Hidráulicas; Ríos; Uso Agrícola; Gobierno Federal; Valles Agrícolas; Medio Ambiente.

The paper addresses the role of the National Irrigation Commission and the Secretary of Hydraulic Resources, the first as a builder, and then both as contractors and supervisors in the construction of dams La Angostura and Alvaro Obregón (Oviáchic), on the Yaqui River, and the Adolfo Ruiz Cortines (Mocúzari), on the Mayo River, in the state of Sonora, Mexico, for agricultural use in the Yaqui and Mayo valleys. Its impact on the environment is also studied.

KeYwords: Hydraulic works; Rivers; Agricultural Use; Federal Government; Agricultural Valleys; Environment.

Copyright: (C) 2019 CSIC. Este es un artículo de acceso abierto distribuido bajo los términos de la licencia de uso y distribución Creative Commons Reconocimiento 4.0 Internacional (CC BY 4.0). 


\section{Introducción}

La Comisión Nacional de Irrigación (CNI) fue fundada por la Ley sobre Irrigación con Aguas Federales de 4 de enero de 1926. Entre otras cosas debía «promover y construir obras de irrigación en la República mexicana». ${ }^{1}$ De esta manera, la propuesta del ingeniero Roberto Gayol, presentada en 1905, en el sentido de que le correspondía al Estado mexicano construir las obras de riego de gran envergadura, se plasmaba. ${ }^{2}$ En la misma tesitura se expresó el ingeniero José Herrera y Lasso, pero dio un paso más adelante, al reconocer que las obras de irrigación traían consigo «alteraciones en el régimen de la propiedad rural; afecta a la clase más numerosa del país, la campesina, modificando sus condiciones de trabajo y de producción y sus relaciones con los propietarios del suelo que cultiva». ${ }^{3}$

En un editorial de la Revista Irrigación en México del mes de junio de 1930, se establecieron las condiciones que debía cumplir el Estado mexicano en la construcción de las obras de riego: «el fraccionamiento forzoso del área regable y su colonización y explotación científicas». ${ }^{4} \mathrm{La}$ idea del ingeniero Gayol de colonizar las nuevas tierras abiertas al cultivo por medio de la irrigación volvía a la palestra. ${ }^{5}$ La irrigación era esencial, en opinión de los técnicos de la CNI, para el avance y ampliación de «la capacidad agrícola del país». ${ }^{6}$ La preeminencia de la agricultura ya había sido reconocida por el secretario de Fomento, Olegario Molina en 1909, al decir que «la minería ya no debería ser considerada como la industria clave de México y que se pusiera ahora toda la atención en los esfuerzos del gobierno dirigidos hacia la agricultura». ${ }^{7}$ Kroeber, de manera acertada, observó una continuidad de la política del régimen porfiriano en su ocaso con la política en la materia de los gobiernos revolucionarios. ${ }^{8}$ La CNI, para cumplir con la encomienda de construir las grandes presas de almacenamiento, emprendió estudios con el propósito de «mejorar el aprovechamiento que se venía haciendo del régimen natural de las corrientes». ${ }^{9}$

\footnotetext{
1 «Ley sobre Irrigación con Aguas Federales», 1926, 99.

2 Gayol, 1994 [1906], 103. En su opinión, el gobierno era «la única entidad que tiene dinero y crédito proporcionado al tamaño de la dificultad que se trata vencer».

3 Herrera y Lasso, 1994 [1919], XXIX-XX.

4 «La política de irrigación del gobierno federal», 1930, 10.

5 Gayol, 1994 [1906], 29-30.

6 «La política de irrigación del gobierno federal», 1930, 9.

7 Kroeber, 1994, 215.

8 Ibidem, 9.

9 Benassini, 1954, 17.
} 
Para esos años de la década de los treinta del siglo pasado, en el valle del Yaqui se contaba con una infraestructura hidráulica construida por las empresas Sonora, Sinaloa Irrigation Company (SSIC) y la Compañía Constructora Richardson, S. A. (CCRSA), a partir de los contratos signados con el gobierno federal, para el uso y aprovechamiento por parte de los colonos de las aguas del río Yaqui en las nuevas tierras abiertas al cultivo. En el contrato que Carlos Conant firmó con el gobierno federal, se estableció que la empresa «podrá construir y formar los receptáculos para hacer la provisión de agua en grandes cantidades, durante las fuertes avenidas de los ríos, a fin de utilizarla en la irrigación, cuando lo crea conveniente». ${ }^{10}$ En el artículo 5 del contrato signado entre el licenciado Rafael L. Hernández y Alberto Stein, de 18 de agosto de 1911, la Compañía Constructora Richardson, S. A (CCRSA) se obligaba a emprender una o varias presas de almacenamiento sobre el río Yaqui, entre Soyopa y la confluencia del río Bavispe. ${ }^{11}$ La citada compañía no cumplió con el compromiso.

El gobierno federal, a través de la Comisión Científica de Sonora, abrió canales para irrigar las tierras de los pueblos yaquis. Los trabajos se realizaron en la última década del siglo XIX y en las primeras décadas del siglo XX. En el caso del valle del Mayo, fueron los propietarios de tierras agrupados en empresas quienes, en su carácter de concesionarios de las aguas del río Mayo, construyeron una infraestructura hidráulica conformada por canales. ${ }^{12}$ En ambos valles se gestó una experiencia en torno a la agricultura bajo riego en una parte de la llanura semidesértica del estado de Sonora. En los dos fueron sangrados los ríos en aras de obtener la potencial riqueza de sus tierras. La participación del gobierno federal en materia hidráulica no sería novedosa en el valle del Yaqui. Ni tampoco su interés por construir una gran presa de almacenamiento sobre el río Yaqui. Sus tributarios son los ríos Aros, Bavispe y Moctezuma. El primero, para el año de 1929, aportaba más de la mitad de las aguas que llegaban al río Yaqui, porque la precipitación es mayor en esa elevación de la cuenca. Las aguas de los dos primeros ríos fluyen por lo abrupto de la Sierra Madre Occidental. La mayor parte de la zona de drenaje del río Bavispe es plana y ondulante.

10 Contrato celebrado entre el C. General Carlos Pacheco, Secretario de Estado y del Despacho de Fomento, en representación del Ejecutivo de la Unión y Carlos Conant, para abrir canales de irrigación en las márgenes de los ríos Yaqui, Mayo y Fuerte, y compra venta de colonización de terrenos, Archivo Histórico del Agua (AHA), Aprovechamientos Superficiales, 4600, exp. 61253, f. 7-9.

11 Contrato celebrado entre la Secretaría de Fomento y la Compañía Constructora Richardson de 18 de agosto de 1911, AHA, Aprovechamientos Superficiales, 290, exp. 6960, f. 11-15.

12 Lorenzana, 2006, 55, 79-84. 
El último río atraviesa valles acotados por cordilleras escabrosas. El río Yaqui en su trayecto hacia el golfo de California pasa por planicies y valles. ${ }^{13}$

El estudio geológico del ingeniero del ingeniero Bond dio cuenta de la presencia en la cuenca de rocas volcánicas como la riolita, el basalto, la andesita y la tufa, así como rocas granulares como el grafito, calcáreas como la piedra caliza y rocas conglomeradas. Además, de una capa de barro gruesa en las cuestas, mesas y en la mayor parte de los valles. La tierra en las inmediaciones de los arroyos es arcillosa y en muchos valles había presencia de bancos elevados de grava. Destacó que en el tramo de doscientos ochenta kilómetros entre las estaciones de aforo de Suaqui-Batuc y Los Limones de la CCRSA, los ríos tributarios del río Yaqui solo llevaban agua en tiempo de crecientes, mucha de la cual se perdía debido a que en el cauce del río había una ancha faja de grava. ${ }^{14}$

El proyecto contemplaba la ampliación del vaso de almacenamiento de la presa ubicada en el sitio El Águila. El propósito era irrigar entre doscientas cincuenta mil y ciento sesenta mil hectáreas en la parte baja de la cuenca. El plan contemplaba desaparecer los pueblos de Suaqui, Tepupa y Batuc. El ingeniero Bond justificó la acción contra aquellos en los siguientes términos: «son pequeños poblados sobre el río Moctezuma con una población de mil seiscientas personas. Las casas en su mayoría son de adobe y las pocas de ladrillo y piedra están en pésimas condiciones». ${ }^{15}$ El citado proyecto hidráulico no se concretó. Por lo tanto, los habitantes de los tres pueblos mencionados no perdieron sus casas y sus tierras. Ello sucedió años más adelante con la construcción de la presa Plutarco Elías Calles o El Novillo por parte de la Comisión Federal de Electricidad. El técnico estadounidense no pasó por alto las vías de comunicación ferroviaria y caminera existentes en algunos puntos de la cuenca del río Yaqui. Los embates contra el medio por parte de las acciones de los seres humanos no llegaron a la mayor parte de la misma, porque únicamente se podía acceder «por medio de veredas que conducen por regiones sumamente accidentadas y escabrosas». ${ }^{16}$

13 Bond, 1935a, 203-205. La precipitación máxima comprendía los meses de julio, agosto y septiembre. Además, la estación de lluvias de invierno, conocidas con el nombre de equipatas, son de corta duración y en algunos años no se registra.

14 Ibidem, 208.

15 Bond, 1935b, 275-276.

16 Bond, 1935a, 206. Las empresas fueron Ferrocarril Noroeste de México, Kansas City and Oriente, Ferrocarril Sud Pacífico de México, un ramal de Estación Corral a Tonichi, Southern Pacific Railway y Ferrocarril de Nacozari. 
Para completar el cuadro del progreso en esta parte de la República mexicana era necesario cumplir con viejo anhelo: la construcción de una gran presa de almacenamiento. El Partido Nacional Revolucionario, en el Plan Sexenal 1934-1940, reconoció que las obras en la materia eran importantes en la política encaminada a lograr el progreso agrícola del país y para la solución del problema agrario, a través de la dotaciones y restituciones de tierras y aguas a los centros de población rural la República mexicana. ${ }^{17}$ Se seguía en el camino diseñado por el presidente Plutarco Elías Calles en torno al problema agrario. Su postura fue la siguiente:

En tanto no se aborde el problema de las tierras de un modo completo e integral, que comprenda no sólo la entrega de la tierra sino la garantía de su producción, haciendo que el que la recibe sea dotado también de las semillas, aguas, implementos y crédito necesarios para el cultivo de las tierras. Ya he dicho que considero el sistema ejidal como un paso para conseguir el desiderátum de extender la pequeña propiedad que hará rica y próspera la agricultura nacional. ${ }^{18}$

Tanto los pequeños propietarios como los ejidatarios eran imprescindibles para el avance de la agricultura al estatus delineado por el presidente Calles. La CNI, acorde con las directrices del Plan Sexenal en materia de irrigación, se comprometió entre otras cosas «al riego de las tierras de las regiones desérticas situadas en el norte del país».$^{19}$ Lo que suponía la modificación del medio a través de la agricultura de riego con el apoyo de obras hidráulicas.

Un grupo de mormones en el marco de la política de colonización del gobierno de Porfirio Díaz llegaron al valle del río Bavispe en 1892. Se abocaron con sus herramientas al desmonte de los mezquites y otros árboles, cuyas maderas las utilizaron como combustible y para la construcción de sus casas y la iglesia-escuela en la Colonia Morelos, cuya fundación fue en 1900. Su arribo no generó ningún conflicto debido a que no afectaron ninguna propiedad. En cambio, el asentamiento sufrió dos incidentes violentos: un atentado con dinamita contra dos tiendas y la escuela iglesia y el incendio del molino harinero, así como el cierre del camino Colonia Morelos-Agua Prieta. ${ }^{20}$ En los terrenos desmontados practicaron la agricultura de riego y el pastoreo de su ganado. Esta última actividad se realizaba en

17 Fabila, 1981, 555-560.

18 Elías Calles, 1988, 155

19 «Nuevas orientaciones de la Comisión Nacional de Irrigación», 1934, 3.

20 Ríos, 2012, 161, 312. 
algunos ranchos establecidos en la zona, con «el sobrepastoreo y la consecuente erosión de las hojas y las barrancas son de aparición general». ${ }^{21}$ Paisajes de la misma índole ya se habían construido en el valle del Mayo desde 1863 y en El Pitic, en las últimas décadas del siglo XVIII y principios del siglo XIX, ${ }^{22}$ y en la década de los años ochenta del último siglo mencionado en el valle de Ures. ${ }^{23}$ La preeminencia de la agricultura fue reconocida por el presidente Lázaro Cárdenas, al decir que era una de las mayores riquezas de México. Asimismo, destacó el trabajo realizado en algunos distritos de riego y la demanda de terrenos irrigables. ${ }^{24}$

Para tratar el tema de la construcción de las grandes presas de almacenamiento sobre los ríos Yaqui y Mayo por parte de la CNI, tema por cierto poco estudiado en la historiografía sobre Sonora y sobre otras de regiones de México, ${ }^{25}$ haremos uso de la historia ambiental «que estudia las transformaciones del medio generadas por procesos de colonización y de explotación mercantil; la introducción de modelos tecnológicos asociados al progreso y a la modernidad; los grandes emprendimientos (petroleros,

21 White, 1948, 239.

22 Bojórquez, 2006, 87.

23 Baroni, 2010, 363, 375

24 Los Presidentes de México..., 1966, 11-12.

25 Los estudios se han centrado en el reparto agrario cardenista en los valles del Yaqui y Mayo (Lorenzana, 1991); en las disputas por el uso agrícola del agua y el papel del Estado en la materia en ambos valles ya mencionados (Lorenzana, 2006) y en Hermosillo en el periodo 1744-1850 (Bojórquez, 2006). Moreno, 2006 se abocó a estudiar la problemática de la sobreexplotación del acuífero de la costa de Hermosillo. Padilla, 2012 abordó el tema de la lucha por el control del agua en la construcción del ejido San Miguel de Horcasitas. Otros temas estudiados por técnicos, historiadores y científicos sociales son las políticas de irrigación porfiriana y callista, encaminadas a mejorar la producción agrícola. Los autores pusieron el énfasis en el papel del gobierno federal como posible constructor de las grandes obras de riego (Gayol, 1994 [1906]; Herrera y Lasso, 1994 [1919]; Kroeber, 1994; Aboites, 1998). Desde el enfoque de la historia regional, un grupo de investigadores destacaron la importancia del agua como un recurso fundamental y escaso en el extremo noreste de México (Cerutti, 1991; Sieglin, 1991; Rodríguez Román, 1991; Olvera Sandoval, 1991; Zebadúa, 1991; Anguiano, 1991). Aboites Aguilar, 1998 se interesó por historiar los principales tramos del camino recorrido por el gobierno federal para erigirse en la principal autoridad gubernamental en el manejo del agua en México y por el despojo de derechos, facultades y prerrogativas de organismos y grupos locales, tanto gubernamentales como privados. Otra vertiente de estudio son los usos sociales del agua en diferentes ámbitos de la República mexicana. Los protagonistas de estas historias son el gobierno federal y los grupos sociales en el manejo y aprovechamiento del recurso agua en la agricultura, la industria y el abasto, así como los conflictos entre los diferentes usos sociales del agua (Castañeda, 1995 y 1998; Suárez, 1998; Birrichaga, 1998; Camacho, 1998). Mentz y Pérez, 1998 exponen los conflictos por el agua y la tierra en dos zonas del actual estado de Morelos. Ya en el siglo XXI, los estudios sobre los usos sociales del agua han continuado (Durán, Sánchez y Escobar, 2005). El análisis del acceso, el control y el manejos de los recursos tierra y agua también han sido del interés de Ávila, et al. (2009). Las problemáticas del agua en cuencas del norte de México, su escasez, gestión, sobrexplotación, fueron del interés de la Red de Investigadores del Agua (Recunor), en 2011 y 2013. 
FIGURA 1

PROYECTOS DE PRESAS SOBRE EL RÍO YAQUI, 1930

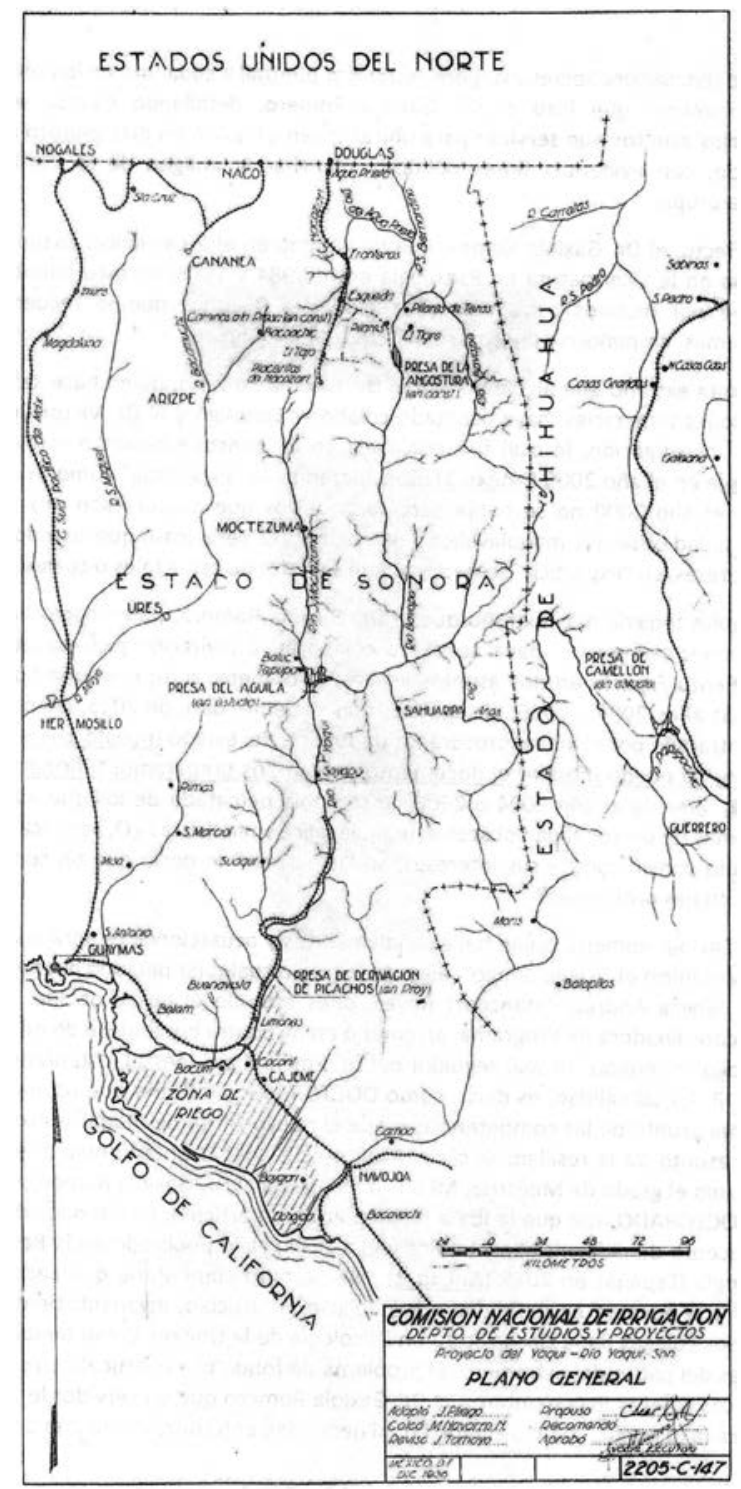

Fuente: Irrigación en México, diciembre de 1937, XV, 1-6, 102. 
ganaderos); la expansión de la frontera agrícola» ${ }^{26}$, así como el enfoque híbrido de la unión de la historia ambiental y la historia de la tecnología, para destacar «las nuevas naturalezas creadas». ${ }^{27}$ En la elaboración de este trabajo se consultaron los acervos documentales del Archivo Histórico del Agua, las Revistas Irrigación en México e Ingeniería Hidráulica en México y periódicos editados en la ciudad de Hermosillo, Sonora. La periodización corresponde al inicio y finalización de los trabajos de construcción por parte de las constructoras nacionales y extranjeras bajo la supervisión de los técnicos de la CNI y de la Secretaría de Recursos Hidráulicos (SRH).

\section{La presa La Angostura o Lázaro Cárdenas, 1936-1942}

Stephen S. White, como parte de sus trabajos de campo en la región del río Bavispe, entre 1938 y 1941, elaboró el siguiente registro del territorio:

Los suelos son en su mayor parte delgados y pedregosos, y los de las tierras bajas son prácticamente de humus. A lo largo de los ríos y en algunos de los cañones más grandes hay depósitos de aluviones que, debido a que son fácilmente irrigados, son las únicas tierras bajas cultivadas. La precipitación invernal varía de 0 a $125 \mathrm{~mm}$, y la precipitación de verano de 250 a $380 \mathrm{~mm}$. En el área del río Bavispe el mezquite forma una banda ancha. La vegetación herbácea más densa se encuentra en la sombra de los mezquites y otros árboles y arbustos. En las tierras aluviales hay mucho terreno desnudo incluso en la estación de lluvias. Las hierbas principales son Sporobolus Wrightii, Hilaria mutica, H. Belangeri, Aristida Adscensionis, B. Rothockii, Echinochloa colonum, Cynodon Dactylon. ${ }^{28}$

Este es el medio que enfrentaron los técnicos de la CNI y las cuadrillas de trabajadores con su arsenal tecnológico compuesto por cemento Portland, acero, concreto reforzado, turbinas, energía eléctrica y bombas de agua, ${ }^{29}$ en su afán de dominar a los ríos y estar en condiciones de dar respuesta a la demanda de la población campesina de terrenos de irrigación, reconocida por el presidente Cárdenas. ${ }^{30}$ En el proyecto de ampliar la frontera agrícola en diversas partes de la República mexicana eran esenciales las grandes presas de almacenamiento. En el caso de los dos valles meridionales de la entidad sonorense, aquellas iban a apuntalar la agricultura bajo riego que, en palabras

26 Leff, 2013, 331-332.

27 Wolfe, 2017 (versión electrónica sin paginación).

28 White, 1948, 236-238.

29 Samaniego, 2006, 132-143.

30 Los Presidentes de México..., 1966, 12. 
de Robert C. West, eran parte del «New» Sonora en contraposición con el «Old» Sonora, representado por los viejos centros mineros. ${ }^{31}$ La idea de construir obras para almacenar las aguas de los ríos en la zona de estudio la expresó Tomás Pelayo en 1804. En su opinión, con obras de ese tipo quedarían a salvo los intereses de los agricultores y las vidas de las personas. Por otra parte, los productores contarían con el recurso agua por varios años. ${ }^{32}$ Dicha idea tuvo seguidores en el transcurso del siglo XIX: Ignacio Zúñiga, ${ }^{33}$ Luis López ${ }^{34}$ y Luis Alfonso. ${ }^{35}$ En el gobierno de Porfirio Díaz, en el valle del Yaqui, se realizó «un ambicioso plan de irrigación y colonización con la participación de instancias del gobierno federal y particulares». ${ }^{36}$

La CNI, en cumplimiento a su atribución de realizar estudios sobre las posibilidades de irrigación en el país, ${ }^{37}$ contrató al ingeniero consultor J. B. Bond. Su propuesta, que ya mencionamos líneas atrás, fue construir en el sitio llamado del Águila la presa de almacenamiento. ${ }^{38}$ Otro sitio seleccionado fue un cañón en La Angostura, situado en el valle de Teras y en medio de las sierras de Teras y Huachinera, en una altura sobre el nivel del mar de 759 metros. ${ }^{39}$ Uno de los posibles afectados por la nueva obra sería Francisco Fragoso, propietario de la hacienda de Teras, quien, además, de contar con más de seiscientas hectáreas para el pastoreo del ganado vacuno, hacía uso de un canal para irrigar cuatrocientas hectáreas en donde cultivaba trigo, maíz, alfalfa y legumbres, que colocaba en el mercado regional. ${ }^{40}$ Manchas de paisajes agrícola y ganadero fueron introducidas en el medio.

La CNI con sustento en los datos recabados eligió el sitio de La Angostura para construir la primera gran presa de almacenamiento sobre el

31 West, 1993, 92. «In essence the "geographical personality" of an area derives from the genre de vie, or way of life, of its inhabitants as adapted to the physical characteristics of the land», Ibidem, xii.

32 Resultados de la subdelegación de Álamos del Real de Los Álamos, 27 de junio de 1804, Biblioteca Nacional de México (BNM), Archivo Franciscano, 36, exp. 36/819.4.

33 Zúñiga, 1835, 40-41. Se declaró partidario de abrir canales de riego.

34 Título de una merced de agua concedida por el Ayuntamiento de Âlamos a favor de Antonio Goycoolea, 10 de marzo de 1873, AHA, Aprovechamientos Superficiales, 1287, exp. 17608, f. 17-19. Para él, la agricultura bajo riego con obras hidráulicas le daría empleo a las clases desvalidas.

35 Velasco, 1893, 73.

36 Padilla, 2017, 81.

37 «Ley sobre Irrigación con Aguas Federales», 1926, 99.

38 Bond, 1935b, 276.

39 Memoria descriptiva del proyecto del río Yaqui, México, D.F., s.f., AHA, Aguas Nacionales, 1 , caja 3890 , exp. 62776, f. 5 .

40 Bond, 1935c, 6. Fragoso tenía una casa, un molino de harina, pajares y bodegas construidos de adobe y ladrillos. Había muchas casas para los trabajadores de la hacienda de construcción económica. 
río Yaqui, proyecto que no pudieron realizar en su momento ni la SSIC ni la CCRSA. La Secretaría de Hacienda y Crédito Público (SHCP) emitió la convocatoria del concurso para la construcción de las presas El Azúcar, Angostura y El Palmito, sobre los ríos San Juan, Yaqui y Nazas, en los estados de Tamaulipas, Sonora y Durango, respectivamente. La constructora Ingeniería y Construcciones Tolteca (ICT), representada por S. W. Stewart, fue la única que presentó una propuesta sobre la presa La Angostura. El monto ofrecido fue superior a los once millones de pesos. ${ }^{41} \mathrm{El}$ presupuesto elaborado por los técnicos de la CNI para la construcción de la presa incluyendo los materiales fue por más de nueve millones de pesos. ${ }^{42}$ La diferencia en los montos, la controversia en el tipo de presa - ITC propuso una de tipo Ambursen en lugar de la presa de arco programada por la CNI- y la poca experiencia de aquella en la construcción de presas del segundo tipo orillaron a la CNI a cerrar el asunto y encargarse de la obra. ${ }^{43}$ La presa La Angostura tuvo como objeto el almacenamiento de las aguas para aprovecharlas en riego y generación de energía eléctrica. La potencial área regable sería de trescientas mil hectáreas. Las obras hidráulicas en ese momento eran la presa de derivación en Los Hornos, un canal principal de setenta kilómetros de longitud que dominaba cincuenta mil hectáreas y canales de distribución que cubrían cuarenta mil hectáreas cultivadas. ${ }^{44}$

La cantidad de hectáreas mencionadas son la evidencia del embate sistemático de los hombres por ampliar la frontera agrícola a costa de la vegetación y fauna originaria de la llanura semidesértica. No conforme con ello, la CNI se abocó a la construcción de la ya citada presa. La altura de su cortina desde la cimentación hasta la corona alcanzaría los 94 metros de altura. ${ }^{45}$ La capacidad del vaso sería de 127 millones de $\mathrm{m}^{3}$; la longitud

41 Acta de la apertura de sobres realizada en México, D.F., 15 de julio de 1936, AHA, Aguas Nacionales, 1, caja 3890, exp. 62776, f. 36-38. A la ICT le adeudaba el gobierno federal más de 97.000 dólares por los trabajos extraordinarios en la construcción de la presa Abelardo L. Rodríguez en Baja California Norte.

42 Costo total de las obras incluyendo proposición y materiales, México, D.F., 5 de agosto de 1936, AHA, Aguas Nacionales, 1, caja 3890, exp. 62776, f. 32.

43 Resumen de las proposiciones recibidas los días 15 y 20 de julio de 1936, en relación con el concurso abierto para la construcción de las presas La Angostura, El Palmito y El Azúcar, México, D.F., 5 de agosto de 1936, AHA, Aguas Nacionales, 1, caja 3890, exp. 62776, f. 5.

44 «istemas de riego», 1937, 101.

45 Memorándum n. 10 enviado por el ingeniero César Jiménez al Vocal Ejecutivo (CNI), México, D.F., 14 de agosto de 1936, AHA, Aguas Nacionales, 1, caja 3890, exp. 62776, f. 106-108. El ingeniero Jiménez, registró las presas de arco más altas del mundo: Boulder y Horse Mesa en Arizona; Diablo Canyon y Ariel en Washington; Pacoima en California; Grissel en Suiza, Shoshone en Wyoming y Owyhee en Oregon. Sus alturas oscilan entre los 222 y 93 metros. 
total de la corona, 185 metros; la longitud de la corona del arco principal, 84 metros y la capacidad del vertedor de demasías, $3.600 \mathrm{~m}^{3} / \mathrm{s}$. La magna obra, además de suministrar el agua para el riego, iba a salvaguardar las vidas y propiedades de los moradores aguas abajo de la presa al controlar las avenidas del río Yaqui. ${ }^{46} \mathrm{El}$ proyecto hidráulico contempló para el vaso de almacenamiento el desmonte de 100 hectáreas, así como la excavación en roca de más de $27.000 \mathrm{~m}^{3} .{ }^{47} \mathrm{La}$ modificación del entorno no se iba a detener, menos aún, con la razón de peso que esgrimió la CNI: la protección de personas y bienes. Tales acciones eran la expresión de la lucha contra la naturaleza que, en el caso de México, era «cuestión de vida y es precisamente por eso por lo que se hace absolutamente necesario contar con hombres capaces de domeñar a la naturaleza, en otras palabras ingenieros». ${ }^{48}$

La idea de la superioridad del hombre sobre el medio permeó en el seno de los ingenieros de la CNI. La ciencia y la técnica fueron los instrumentos para lograr dicho objetivo. En esta tarea fue indispensable el cemento de bajo calor, el cual se importaba de los Estados Unidos. Con la finalidad de superar tal situación el ingeniero Francisco Vázquez del Mercado, vocal ejecutivo de la CNI, eligió a la fábrica Cemento Portland Nacional con sede en Hermosillo, capital del estado de Sonora, como proveedora del material. Estaba conectada con una espuela al ferrocarril Sud-Pacífico. Se ubicaba al sur de la citada ciudad a una distancia de seis kilómetros. En los alrededores de sus instalaciones se localizaban las materias primas: yacimientos de caliza y granito desintegrado. A una distancia mayor estaban los yacimientos de óxido de fierro, el cual era transportado en camiones a la fábrica. Además de la embestida contra los yacimientos la fábrica contaminaba con la expulsión de polvo por su chimenea. Para atender la demanda de alrededor de cuarenta y seis mil toneladas de cemento que se necesitaban para la construcción de la presa La Angostura se le iban a hacer mejoras a la planta. ${ }^{49}$ La conjunción de los materiales en obras de tal envergadura «habrá asegurado para la región noroeste del país una inagotable fuente de riqueza ya que las tierras del valle del Yaqui están consideradas entre las de mejor calidad en el mundo y son excelentes para el cultivo del algodón,

46 Memorándum al Vocal Ejecutivo (CNI), México, D.F., 21 de septiembre de 1936, AHA, Aguas Nacionales, 1, caja 3890, exp. 62776, f. 130.

47 Presupuesto comparativo del proyecto presentado en agosto de 1936 por la Ambursen Dam Co., para la Angostura, Río Yaqui, México, D.F., 21 de septiembre de 1936, AHA, Aguas Nacionales, 1, caja 3890, exp. 62776, f. 152.

48 Jiménez, 1937, 4.

49 «Fabricación de cemento Portland...», 1938, 39, 41, 44. 
trigo, arroz y otros productos». ${ }^{50}$ Las palabras anteriores sólo recogieron la percepción que prevalecía entre los agricultores de los valles del Yaqui y el Mayo, desde décadas atrás, en torno al potencial de las tierras bajo riego.

La CNI para el traslado de hombres, materiales y equipo al cañón de La Angostura abrió un camino entre la Estación Tajo del Ferrocarril Nacozari-Agua Prieta y el sitio de construcción. En la apertura del camino de terrecería de una extensión de más de cincuenta kilómetros sobre un terreno accidentado — Sierra del Tigre—, se desmontó el matorral subinerme y se instalaron tres puentes (en los kilómetros 19, 30 y 44) y 143 alcantarillas. El nuevo paisaje carretero fue acompañado por los postes del tendido de la línea telefónica entre el pueblo de Esqueda y la zona de construcción. Los trabajos específicos de la gran obra dieron inicio en enero de 1936. Uno de ellos fue la desviación del río Bavispe, cuyas aguas y las de sus afluentes drenaban una gran parte de la Sierra Madre Occidental debido a las precipitaciones abundantes en los meses de julio a octubre. Tal volumen en ocasiones inundaba el delta del río Yaqui. En la temporada de secas, de abril a junio, proporcionaba poca agua para el riego. ${ }^{51}$

Félix Verdugo, vecino del pueblo de Onavas, señaló a finales del siglo XIX que el ancho del cauce del río Yaqui en tiempos de lluvias llegaba a los doscientos metros, con una profundidad de cuatro metros. En tiempos de secas, sólo alcanzaba los cincuenta metros de ancho con una hondura de cincuenta centímetros. ${ }^{52}$ Por su parte, J. A. Salido, prefecto del distrito de Álamos, dijo que el ancho del cauce del río Mayo enfrente de los pueblos de Huatabampo, Etchojoa, San Pedro, San Ignacio Cohuirimpo y Navojoa variaba entre doscientos y doscientos cincuenta metros. Las tierras irrigadas por las avenidas fueron utilizadas por los yaquis y los mayos en la práctica de la agricultura. ${ }^{53}$

Las avenidas trajeron consigo la destrucción de las milpas, la pérdida de ganado y el despoblamiento de algunos pueblos. ${ }^{54}$ Las crecientes de ambos ríos han sido parte de una historia de desastres sociales en 1911, 1914, 1923, $1925^{55}$

50 Memoria del Distrito de Riego del Río Yaqui elaborada por el ingeniero Armando Riemann, México, D.F., 10 noviembre de 1940, AHA, Consultivo Técnico, 1, caja 852, exp. 8014, f. 6.

51 West, 1993, 106.

52 Respuesta de Felix Verdugo al cuestionario de la Secretaría de Fomento de 25 de septiembre de 1897, Archivo General del Estado de Sonora, Prefecturas, 458, f. 56.

53 Padilla, 2017, 79

54 Comunicación de José María Almada al gobernador del estado de Sonora de 28 de noviembre de 1834, Archivo General de la Nación, México (AGN), Tierras, volumen 3601, f. 95.

55 Ibidem, f. 87. 
y en años más recientes. Es un tema por indagar. También tenemos registro de la escasez de agua. José Joaquín de Zayas, cura del pueblo de la Natividad de Navojoa, escribió en su informe de agosto de 1772, que los mayos del citado pueblo y de San Ignacio Cohuirimpo padecían hambre por la pérdida de sus siembras por la falta de agua en el río Mayo. ${ }^{56} \mathrm{~A}$ principios del siglo XIX, el subdelegado del Real de Álamos, Tomás Pelayo, registró la falta de agua en el curso del río Mayo «por más de veinte leguas durante los meses de abril, mayo y junio». ${ }^{57}$ Los fenómenos meteorológicos de la abundancia o escasez de lluvias son de larga data en la entidad sonorense. Las grandes presas no iban a resolver tales fenómenos pero sí iban a permitir el control de las avenidas y el suministro del recurso agua para los agricultores.

El campamento se instaló en una loma después de la tala de árboles a más de doscientos metros de la margen derecha del río Bavispe. Con la madera se edificaron las oficinas y los alojamientos de los técnicos y trabajadores. La descarga las aguas negras se haría en el arroyo El Carricito. ${ }^{58}$ Estas acciones eran minimizadas por «la cruzada de redención económica en que hombres abnegados y heroicos, inspirados en el bello ideal de buscar bienestar y la grandeza de la patria, luchando día a día, desafiando peligros, soportando las inclemencias de los elementos y sufriendo privaciones sin fin, para realizar el prodigio de convertir tierras agrestes en campos cultivables». ${ }^{59}$

La lucha contra el medio era superior a cualquier inconveniente que enfrentaran los ingenieros y los trabajadores de la CNI. Los esfuerzos realizados hasta ese momento en la materia no habían sido suficientes para controlar las corrientes fluviales torrenciales, que se perdían en el mar. Ello no fue una traba para que al interior de la CNI se siguiera insistiendo en dominar a la naturaleza. Incluso se alzó una voz profética: «los ríos con su agua vivificante son las arterias de la vida de la Nación Mexicana y el uso o desperdicio de sus aguas significará en el futuro como ha significado siempre en el pasado, el progreso o atraso de las regiones que cruzan». ${ }^{60}$ En la edición del periódico hermosillense El Pueblo del 1 de septiembre de 1940 se destacó la mencionada obra con las siguientes palabras: «El más

56 Informe señalando las causas por las cuales los indios del río Mayo no pagan tributos, agosto de 1772, AGN, Provincias Internas, 17, f. 143.

57 Resultados de la subdelegación del Real de Los Álamos de 27 de junio de 1804, BNM, Archivo Franciscano, 36, exp. 36/819.4.

58 Presupuesto del proyecto de la cortina de arco, México, D.F., 21 de septiembre de 1936, AHA, Aguas Nacionales, 1, caja 3890, exp. 62776, f. 156.

59 Ortega, 1938, 5.

60 Gómez, 1940, 5, 9. 


\section{FIGURA 2}

\section{CAMPAMENTO DE LA ANGOSTURA, 1937}

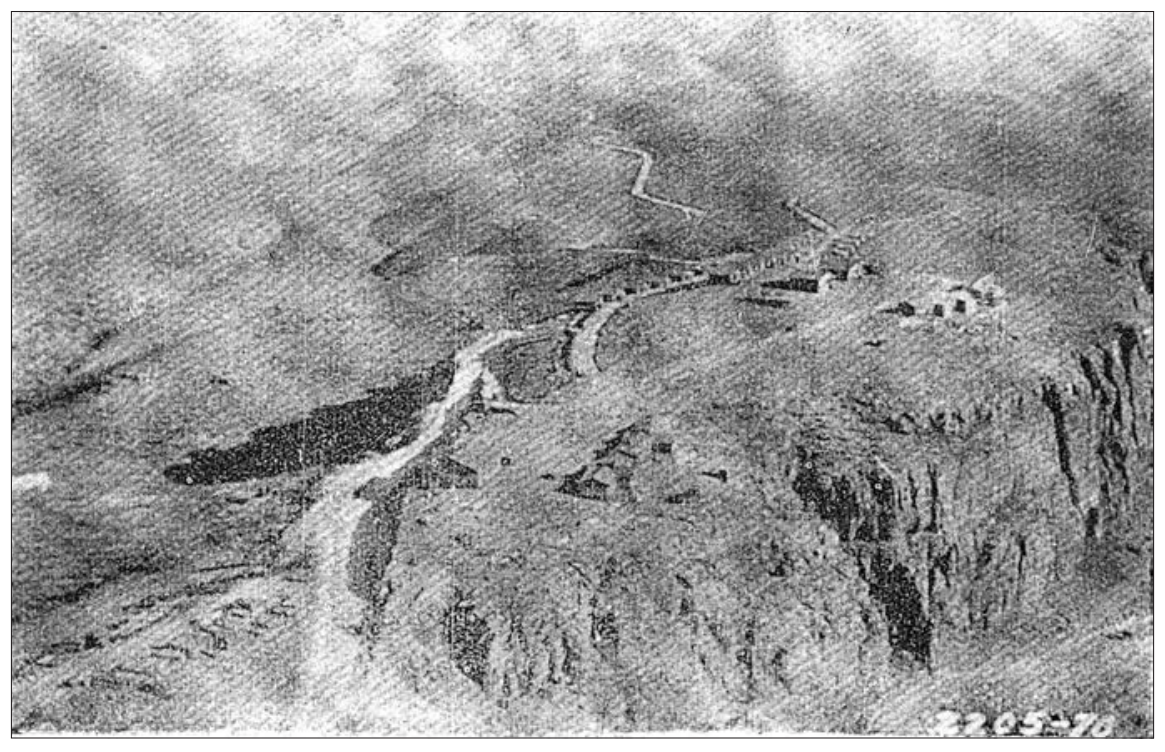

Fuente: Irrigación en México, julio-diciembre 1937, volumen XV, números 1 al 6, p. 103.

grande y sensacional paso del progreso de Sonora es incuestionablemente la construcción de la monumental presa Angostura, obra que lleva a cabo el gobierno del presidente Lázaro Cárdenas, con la cual, se podrán irrigar unas trescientas mil hectáreas». ${ }^{61}$ En la edición del 13 de noviembre de 1940 del citado periódico, se reprodujo la siguiente nota fechada el 5 de noviembre en la ciudad de México:

Después de cuatro años de intensa lucha contra los elementos opuestos de la naturaleza y venciendo innumerables obstáculos entre los que se contó en un principio con la dificultad para las comunicaciones, motivo por el cual tuvo que construirse un camino que va de la estación del Tajo hasta el sitio de la cortina, atravesando por lo más intrincado de la serranía sonorense. La cortina de la presa tiene una altura de 88 metros con 75 centímetros, colocándose hasta septiembre del año en curso, 170, 354 $\mathrm{m}^{3}$ de concreto, dato suficiente para dar una idea exacta de la magnitud de la obra. ${ }^{62}$

61 «Doce meses de progreso», El Pueblo, Hermosillo, Sonora, 1 de septiembre de 1940, 1.

62 «Trabajos finales en la construcción de la cortina de la presa Angostura», El Pueblo, Hermosillo, Sonora, 13 de noviembre de 1940, 1. 


\section{FIGURA 3}

TRABAJOS EN LA PRESA LA ANGOSTURA, 1938

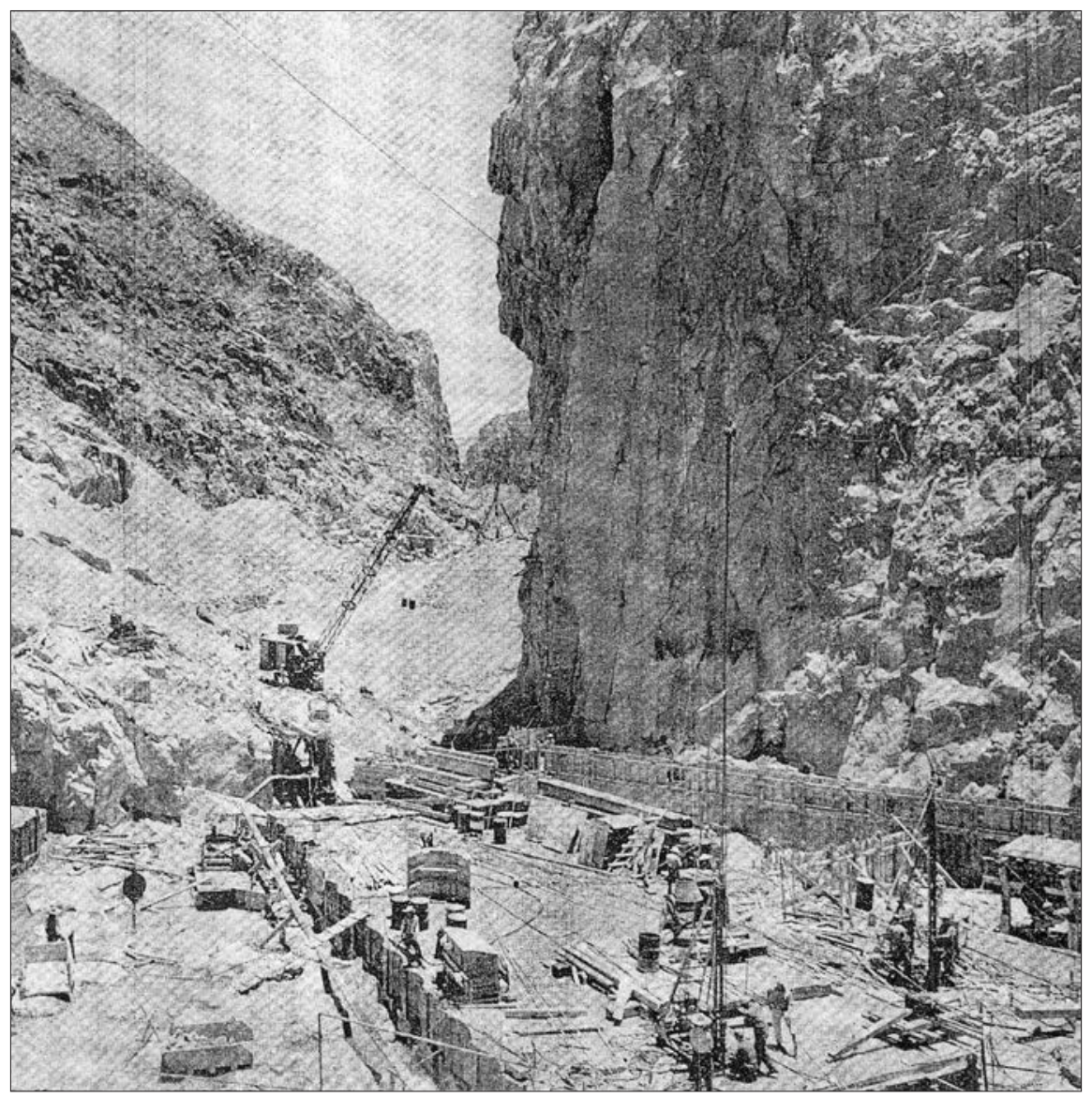

Fuente: Irrigación en México, septiembre-octubre 1938, volumen 18, número 2, portada.

Ambas notas periodísticas dan cuenta de un discurso triunfalista que no era compartido por los habitantes de los pueblos del río Bavispe. La citada presa desde la óptica de la CNI era la primera etapa del desarrollo de la cuenca del río Yaqui. La segunda etapa contemplaba la construcción de la presa de Camellón sobre el río Papigochic en Chihuahua. En la tercera 
etapa se iba a construir la presa de El Águila sobre el río Yaqui. ${ }^{63}$ Desde los inicios de los trabajos en 1936, los habitantes de los pueblos ribereños del río Bavispe se inconformaron porque ellos sabían que ya no iban a fluir las aguas sobre el lecho del río, causa por la cual sus tierras ya no serían irrigadas. De manera organizada y sin realizar ningún acto de violencia, exigieron a los responsables de la obra el suministro del recurso agua para uso agrícola. Aquellos, con la intención de no empeorar la situación, autorizaron la salida del agua por un tubo de doce pulgadas. A un mes, los vecinos del pueblo de Oputo - hoy Villa Hidalgo_-, el más cercano a la presa, expresaron que no había «llegado ni siquiera un hilito; toda el agua ha sido consumida por el lecho arenoso y seco del río». ${ }^{64}$

Durante los trabajos de construcción de la cortina fueron despedidos cientos de obreros por parte de la empresa contratista. Ante la presión de los afectados, se vio obligado el gobernador Román Yocupicio a solicitar la ayuda del presidente Lázaro Cárdenas para su reinstalación o «reasignarlos en otros lugares o ciudades». ${ }^{65}$ La terminación de la primera gran presa de almacenamiento en Sonora fue celebrado por el secretario de Agricultura y Fomento, representante presidencial y el gobernador Anselmo Macías. En cambio, «cincuenta y nueve familias del pequeño pueblo de Casa de Teras, que cultivaban comunalmente un ejido del mismo nombre, sufrieron las peores imposiciones al ser desplazados de sus tierras y su hogar». ${ }^{66}$ Aquellos, como no pudieron dar marcha atrás a la gran obra hidráulica esperarían, al igual que los técnicos de la CNI, las lluvias abundantes de verano durante varios años para el llenado del vaso de almacenamiento de la presa La Angostura. Solo entonces se daría el desfogue de agua sobre la cortina $\mathrm{y}$, con ello, el flujo de las aguas sobre el cauce del río Bavispe. Mientras ese momento llegaba, los afectados con el respaldo de los gobernadores Anselmo Macías y Abelardo L. Rodríguez le solicitaron a la CNI la liberación del «liquido precioso». ${ }^{67}$ No olvidemos, la prioridad para el gobierno federal era no únicamente irrigar las tierras de la llanura semidesértica sino también ampliar la frontera agrícola. La nueva presa quedó bajo la administración de la CCRSA, cuyo control lo tenía el Banco Nacional de Crédito

63 «Las obras de la Comisión Nacional de Irrigación», 1940, 133-134.

64 «Están haciendo negocio brillante con el bombeo de la presa La Angostura», El Pueblo, Hermosillo, Sonora, 18 de agosto de 1941, 1.

65 Sterling, 2006, 62.

66 Ibidem, 64. También los pequeños agricultores de los municipios de Oputo, Granados y Huásabas se vieron afectados por el cambio de la dirección de la corriente, 66.

67 Ibidem, 67-68. 
Agrícola. Los usuarios de las aguas contenidas en la presa reconocidos en el acuerdo fueron los colonos y las colonias yaquis. ${ }^{68}$

A los nuevos ejidatarios del valle del Yaqui, para acceder al recurso agua para uso agrícola, se les dio la posibilidad de firmar contratos con la CCRSA. Ellos, por supuesto, no procedieron en esa dirección y solicitaron, vía oficios entregados en diversas instancias del gobierno federal, la entrega del agua de manera gratuita, a lo cual se negó dicha compañía. En el caso de las colonias yaquis, la CNI iba a construir un canal principal, canales secundarios, drenaje y caminos para el riego de diez mil hectáreas en la margen derecha del río Yaqui. ${ }^{69}$ A pesar de estas asignaturas pendientes, la multicitada presa sirvió para regular la descarga del río Yaqui, de modo de que hubiese agua disponible para el riego todo el año. De esta manera, se reafirmó la «personalidad geográfica» de la zona llamada «New» Sonora. ${ }^{70}$

\section{La presa Oviachic o Álvaro Obregón, 1946-1952}

En el Plan Sexenal 1941-1946 elaborado por el Partido de la Revolución Mexicana, continuó siendo prioritaria la conservación y construcción de obras de riego, así como la desecación de lagunas para abrir nuevas tierras al cultivo o para construir vías de comunicación, obras de bonificación de tierras empobrecidas y recuperación de terrenos afectados por erosiones. El propósito fue impedir el avance de tales fenómenos. ${ }^{71}$ En el periodo del presidente Manuel Ávila Camacho se proyectó abrir al cultivo más de 437.000 hectáreas, casi cuatro veces más que en los años $1926-1940 .{ }^{72} \mathrm{El}$ presidente Miguel Alemán Valdés, al igual que sus antecesores, reiteró el deseo alcanzar el bienestar de la nación, el cual «requiere el aumento de la producción agrícola para lo que es fundamental el desarrollo de las obras de riego que restarán a la eventualidad de las sequías extensiones cultivables». ${ }^{73}$ Las grandes presas de almacenamiento servirían como medio para atenuar los efectos del citado fenómeno meteorológico.

68 «Acuerdo previniendo que se entrega...», 1942, 11-12.

69 «rograma sexenal», 1942, 20.

70 West, 1993, 106.

71 Segundo Plan Sexenal, 1941-1946, s. a., 53-54. Se mantenía la política de protección a los bosques, sumándoles la forestación y la reforestación. Además, por medio de plantaciones especificas se le aseguraría la provisión de materia prima a la industria del papel.

72 Orive, 1942, 5. Desde 1926 hasta 1940 las nuevas hectáreas fueron más de 156.000

73 Los Presidentes de México..., 1966, 355-356. 
Para enfrentar dicho reto se debía continuar con las etapas programadas en el proyecto hidráulico del río Yaqui, ya mencionadas. El sitio elegido para una nueva presa fue «el estrechamiento que se forma entre los cerros del Oviáchic y la Cantera, situados en la margen derecha y en la margen izquierda respectivamente». ${ }^{74}$ Los estudios geológicos del sitio los realizó el doctor Paul Waitz, en el mes de mayo de 1942. A la par de los datos técnicos, destacó el ancho del cauce del río de trescientos metros en el pueblo de Buenavista y que en una parte de la vasta llanura semidesértica, «hoy en día ya se riegan considerables extensiones de tierras con las aguas que aporta el río, pero cuyas dilataciones se podrán aumentar en gran escala cuando se contará con el almacenamiento conveniente de los enormes caudales que escurren por el río en las estaciones de las lluvias de verano e invernales y que actualmente se pierden inaprovechadas en el golfo». ${ }^{75}$

El mencionado técnico destacó la abundancia del agua que fluía por el cauce del río Yaqui hacia la costa, sin que fuese aprovechada por los seres humanos. En aras de terminar con dicha dilapidación era pertinente su almacenamiento en nueva presa a más de trescientos kilómetros de la presa La Angostura. A lo estratégico del sitio los técnicos le asociaron las siguientes razones: el acceso al sitio por ferrocarril —Estación Corral a Tonichi- y por carretera, así como la distancia de cuarenta kilómetros al norte de Ciudad Obregón y del núcleo de tierras agrícolas. Con esta última condición, esperaba tener un mejor aprovechamiento de las aguas del río Yaqui en el distrito de riego del mismo nombre. ${ }^{76}$

La noticia de la nueva presa se dio a conocer en las páginas del periódico hermosillense El Imparcial. La premisa de la CNI en el caso de la entidad sonorense era aprovechar «los recursos hidráulicos de los ríos Yaqui y Mayo, mediante la construcción de presas con un volumen de almacenamiento de aproximadamente 4.000 millones de metros cúbicos», con el propósito de «formar la unidad agrícola de mayor importancia en el país». ${ }^{77}$ Tal expectativa llevó a realizar una ceremonia de inauguración de los trabajos de excavación para colocar los cimientos de la nueva presa con

74 Geología del sitio de Oviachic México, D.F., 2 de enero de 1955, AHA, Aguas Nacionales, 1, caja 3890, exp. 62776, f. 70

75 Informe del doctor Paul Waitz sobre las condiciones geológicas de la boquilla del Oviachic, México, D.F., 12 de mayo de 1942, AHA, Consultivo Técnico, 1, caja 845, exp. 7966, f. 103-104.

76 Memorándum sobre el Distrito de Riego del Río Yaqui, México, D.F., 15 de agosto de 1973, AHA, Aguas Nacionales, 1, caja 3890, exp. 62776, f. 62.

77 «Grandes obras para los ríos Yaqui y Mayo», El Imparcial, Hermosillo, Sonora, 16 de septiembre de 1946,1 . 
la detonación de varias cargas explosivas, el 16 de noviembre de 1946, con la presencia del gobernador de Sonora, Abelardo L. Rodríguez y del secretario de Agricultura, Marte R. Gómez. ${ }^{78}$ Con el nuevo proyecto hidráulico se pensó ampliar la frontera agrícola en doscientas mil hectáreas, que se sumarían a las cien mil que ya se irrigaban con las aguas almacenadas en la presa La Angostura. También al igual que la presa La Angostura, su intención era controlar las avenidas de la ya citada corriente superficial. ${ }^{79}$

El secretario de Agricultura, Marte R. Gómez, consideró que «las presas eran la salvación de la agricultura y ganadería». ${ }^{80}$ De esta manera, el gobierno federal mantenía su compromiso de suministrar el recurso agua por varios años a los agricultores y ganaderos, a pesar de la irregularidad de las lluvias de verano e invierno en la entidad sonorense. No está por demás reiterar que ambas actividades humanas son modificadoras del medio. Debido a la relevancia del uso y aprovechamiento de las aguas de las corrientes superficiales de México, el presidente Miguel Alemán Valdés creó la Secretaría de Recursos Hidráulicos (SRH) en sustitución de la CNI, el 1 de diciembre de 1946. Se le dieron, entre otras tareas, «la definición de las políticas para el correcto funcionamiento del agua potable y de riego», ${ }^{81}$ así como la elección de los sitios para la construcción de las grandes presas de almacenamiento y la supervisión de los trabajos de construcción.

El ingeniero Adolfo Orive Alba, secretario de Recursos Hidráulicos, ya con la elección del sitio, emitió la convocatoria para la construcción por contrato de la presa Álvaro Obregón sobre el río Yaqui. ${ }^{82}$ Las empresas que atendieron el anuncio fueron la Compañía Morrison \& Knudson, Urbanizaciones, S. A. y la Compañía Constructora Roscoff, S. A. La propuesta de la primera fue por más de 92 millones de pesos, la segunda ofertó por más de 88 millones y la tercera superó los 132 millones. La decisión del jurado —integrado por el ingeniero J. Vicente Orozco, jefe de irrigación; el ingeniero Andrew Weis, jefe del departamento consultivo; el ingeniero consultor, Antonio Coria; el licenciado Benito Loyola, jefe de la dirección

78 Telegrama del ingeniero Alberto Barnetche G. al ingeniero Antonio Coria, Ciudad Obregón, Sonora, 18 de noviembre de 1946, AHA, Consultivo Técnico, 1, caja 845, exp. 7966, f. 12.

79 «resa Álvaro Obregón (El Oviáchic)», s. a., 27.

80 «Declaraciones del Secretario Marte R. Gómez», El Imparcial, Hermosillo, Sonora, 16 de noviembre de 1946,1 .

81 Escobar, 2009, 70.

82 Circular relativa a la convocatoria dirigida a ingenieros y compañías interesadas en presentar proposiciones para la construcción por contrato de la presa Álvaro Obregón sobre el río Yaqui, México, D.F., 14 de marzo de 1947, AHA, Consultivo Técnico, 1, caja 786, exp. 7505, f. 3-5. 
consultiva legal; el ingeniero consultor, Max W. King; Augusto de Yta, director general de construcción, e Ignacio de la Cajiga, jefe del departamento de contratos - fue a favor de Urbanizaciones, S. A, por presentar el presupuesto más bajo. ${ }^{83}$

La obra contemplaba la cortina, el vertedor, la toma alta y la toma baja, así como el campamento de residencia y todas las obras auxiliares. Los trabajos deberían dar inicio el 5 de septiembre de 1947 y deberían terminar el 5 de marzo de $1952 .{ }^{84}$ La CNI emplazó a los socios de Urbanizaciones, S. A. a comprobar su solvencia económica y de equipo para llevar a cabo una obra de tal envergadura. ${ }^{85}$ El 27 de julio de 1947, aquella presentó ante la CNI la documentación correspondiente, por lo tanto el presidente de México, Miguel Alemán Valdés, le adjudicó el contrato ${ }^{86}$ El ingeniero Manuel Bustamante quedó como responsable de los trabajos por parte de la constructora y los ingenieros Alberto Barnetche y José Hernández Terán, gerente general de irrigación en el Estado de Sonora e ingeniero residente respectivamente, fueron los supervisores de la obra.

Francisco Coronado Limón, habitante del pueblo de Buenavista fue testigo de las acciones de la citada constructora: «aplanó terrenos, introdujo cables, construyó una pequeña ciudad, Urbanizaciones, atentó contra los montes, arrasó las alamedas y a los mezquites los hizo carbón. Los animales se fueron a otras madrigueras». ${ }^{87}$ Además de provocar la desviación del río y el desmonte de la vegetación originaria. Los materiales pétreos y la tierra para la obra se obtuvieron de los cerros La Cantera y del Potrero así como de las terrazas, la tierra ubicada en las orillas del vaso Buenavista, que tenían abundante vegetación arbustiva. El campamento de la CNI se

83 Memorándum relativa a la revisión de las propuestas presentadas por los competidores del contrato de la presa Oviachic, México, D.F., 28 de abril 1947, AHA, Consultivo Técnico, 1, caja 786, exp. 7505 , f. 31-35.

84 Contrato para la construcción de la presa Oviachic, México, D.F., s.f., AHA, Consultivo Técnico, 1, caja 786, exp. 7505, f. 39-76.

85 Oficio del ingeniero Adolfo Orive Alba, secretario de Recursos Hidráulicos, a la Compañía Urbanizaciones, S. A., México, D.F., 10 de julio de 1947, AHA, Consultivo Técnico, 1, caja 786, exp. 7505, f. 101-102. La fecha límite que le establecieron fue el 26 de julio de 1947.

86 Discurso del ingeniero Adolfo Orive Alba, secretario de Recursos Hidráulicos pronunciado en la presa Álvaro Obregón, Sonora, 4 de abril de 1948, AHA, Aguas Nacionales, 1, caja 3890, exp. 62776, f. 6. La maquinaria con que contaba Urbanizaciones S.A. era la siguiente: dos palas, una draga, quince camiones Euclid, perforadoras con sus compresores de aire, pistolas de mano, dos escrepas jaladas con tractor D8, cinco tractores D8 con cuchilla empujadora, tres bombas de seis pulgadas, tres motoconformadoras, una clasificadora de agregados para concreto, un camión pipa regadora, seis juegos de rodillos pata de cabra, AHA, Consultivo Técnico, 1, caja 786, exp. 7505, f. 235.

87 Murrieta, s. a., 200-201. La palabra monte se utiliza para denominar los terrenos con abundante vegetación. 
levantó en el sitio llamado Los Limones, después de desmontar una parte de la planicie, en las cercanías del cerro El Potrero. ${ }^{88}$ La sociedad sonorense se enteró de la construcción de la nueva presa sobre el río Yaqui por la nota publicada en las páginas del periódico El Imparcial:

La cortina sería tipo de tierra [y roca]. Su extremo derecho iniciaría en el cerro del Oviáchic y el extremo izquierdo en el cerro de La Cantera. Llevará un corazón de material impermeable y el resto se formará con material graduado, utilizando el existente en los bancos formados por el propio río. Su altura será de 50 metros con una longitud de corona de 1400 metros. Tendrá túneles de extracción que se construirán de hormigón armado. El vertedor de demasías quedará localizado en un pequeño puerto limitado por dos protuberancias en la margen derecha del río Yaqui con una longitud de 900 metros. ${ }^{89}$

FIGURA 4

PLANO DE LA PRESA OVIACHIC, 1955

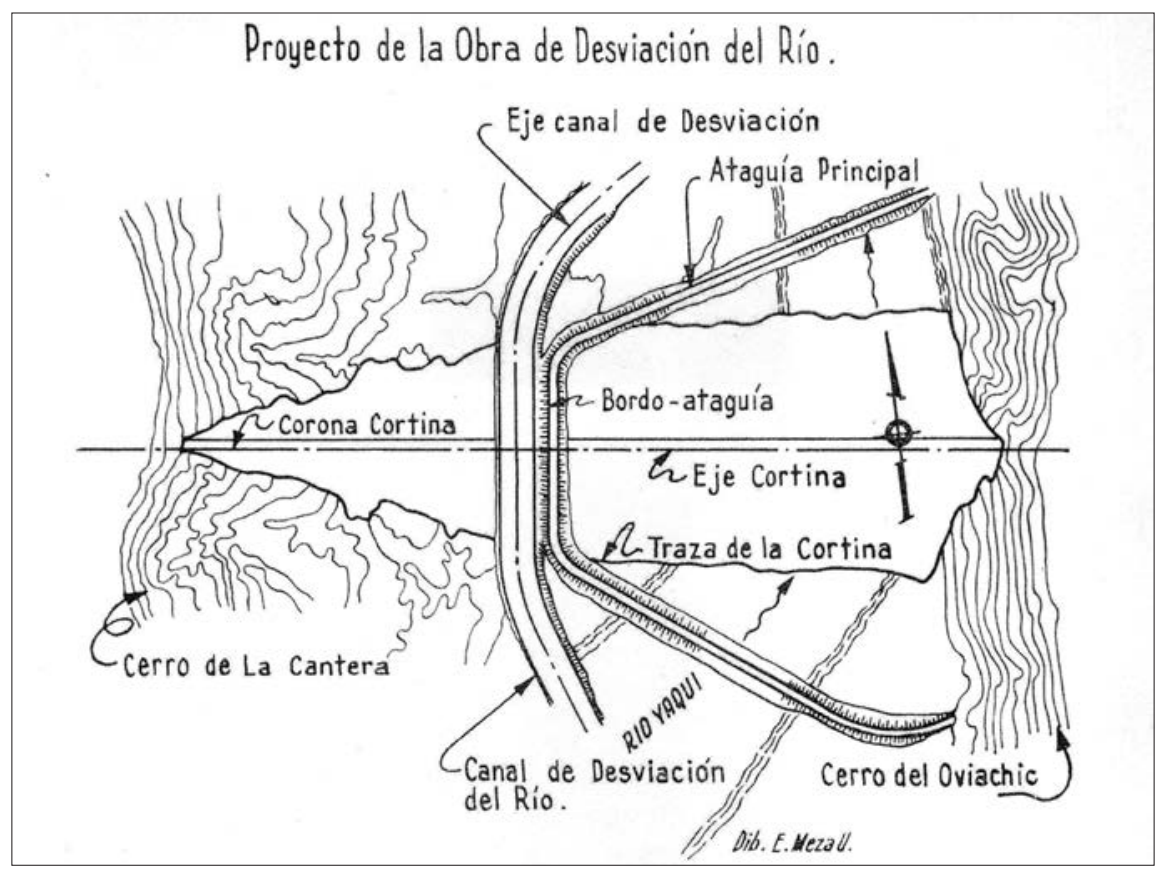

Fuente: Ingeniería hidráulica en México, abril-junio, volumen IX, número 2, p. 57.

88 Fotografías de los cerros Oviachic, La Cantera y El Potrero y el campamento Los Limones, s.f., AHA, Aguas Nacionales, 1, caja 3890, exp. 66776, f. 14-15.

89 «La presa Álvaro Obregón», El Imparcial, Hermosillo, Sonora, 16 de septiembre de 1947, 1. 
Después de varios meses de trabajo, el 4 de abril de 1948, se realizó la inauguración oficial de los trabajos por parte del ingeniero Adolfo Orive Alba, secretario de Recursos Hidráulicos. En su alocución, dijo que la capacidad de la presa del Oviachic sería de tres mil millones de metros cúbicos para irrigar cerca de trescientas mil hectáreas. La inversión sería del orden de los cien millones de pesos. En su construcción se iban a requerir nueve millones de metros cúbicos de tierra y roca. En su opinión, este tipo de obras de gran magnitud tenían como propósito «crear bienestar para los mexicanos y riqueza para el país y la presa del Yaqui estamos seguros que lo va a hacer por la calidad del material humano que va a explotar las tierras, por la calidad de los campesinos y de los agricultores que han sabido siempre trabajar estas tierras inhospitalarias con duro trabajo, de manera de sacar a la tierra sus frutos». ${ }^{90}$

El funcionario federal seguía con la idea de dominar a la naturaleza, la cual, ya la había expresado Ignacio Zúñiga en los años treinta del siglo XIX en los siguientes términos: «sangrasen los ríos, establecieran plantaciones y se aprovechen de cuanto sea posible de una tierra virgen y poblada de miles de brazos, hoy inútiles y perjudiciales». ${ }^{91} \mathrm{La}$ aspiración de modificar la llanura semidesértica sonorense, venía de varias décadas atrás. Las lluvias torrenciales ocurridas en el mes de enero de 1949 aumentaron el caudal del río Yaqui que arrasó con todo a su paso. ${ }^{92}$ Como después de la tempestad viene la calma, los trabajos de la construcción de la presa Oviachic se reanudaron hasta una nueva suspensión, ahora por un paro de los trabajadores asignados a la apertura del canal Alto, obra ubicada aguas abajo del embalse. La causa fue la muerte de varios trabajadores a consecuencia de los derrumbes de las piedras provocados por el uso de dinamita. ${ }^{93}$ Finalmente, el 28 de febrero de 1952, la cortina de tierra y roca de la presa Álvaro Obregón fue terminada. Ante miles de personas, el 15 de octubre de 1952, las autoridades inauguraron la nueva presa con capacidad de 2.989 millones de metros cúbicos. ${ }^{94}$

90 Discurso del ingeniero Adolfo Orive Alba, secretario de Recursos Hidráulicos pronunciado en la presa Álvaro Obregón, Sonora, 4 de abril de 1948, AHA, Aguas Nacionales, 1, caja 3890, exp. 62776, f. 5-7. Asimismo, anunció el uso de la presa La Angostura para generación de energía eléctrica. El ingeniero Octavio Leyte realizó los siguientes pronósticos de la producción agrícola: Dos centenares de miles de toneladas de trigo y más de cien mil toneladas de arroz.

91 Zúñiga, 1985, 40-41.

92 «uertes lluvias en el río Yaqui», El Imparcial, Hermosillo, Sonora, 11 de enero de 1949, 1.

93 «roblemas laborales en las obras de la presa Oviachic», El Imparcial, Hermosillo, Sonora, 23 de enero de $1952,1$.

94 «e terminó la cortina de la presa Álvaro Obregón», El Imparcial, Hermosillo, Sonora, 16 de octubre de $1952,1$. 


\section{FIGURA 5}

TRABAJOS EN LA PRESA OVIACHIC, 1955

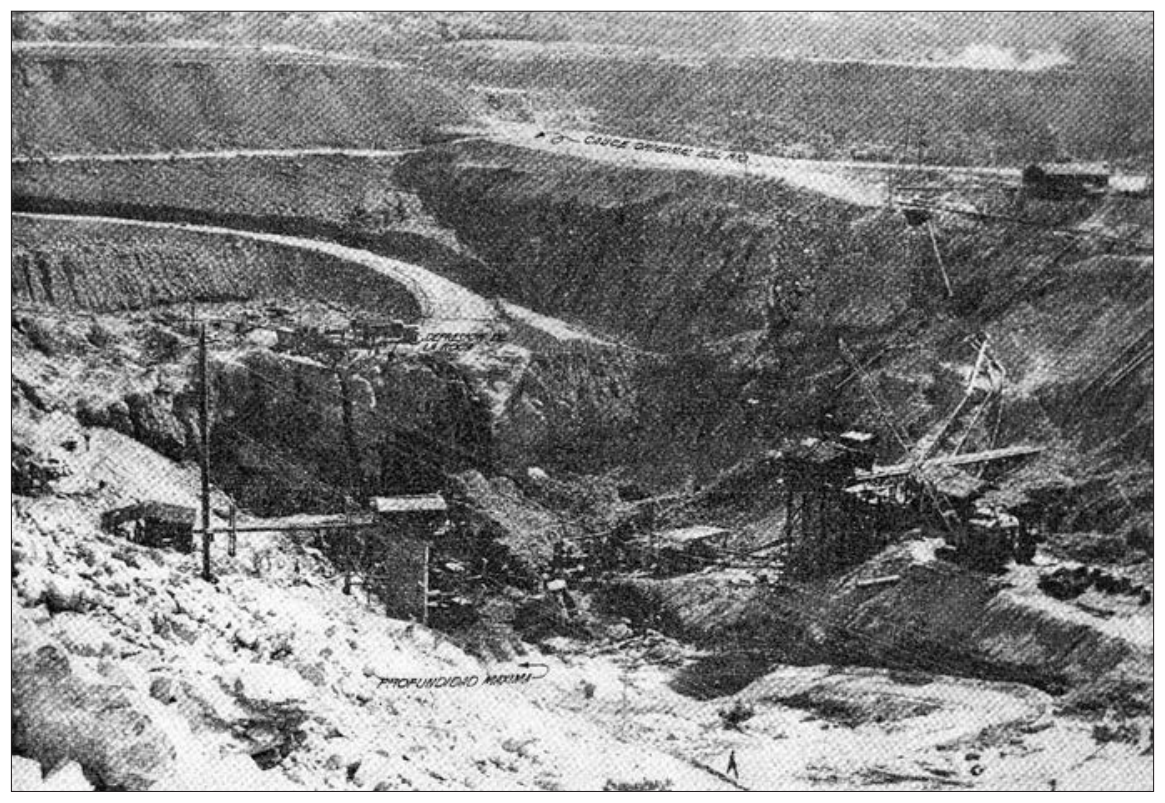

Fuente: Ingeniería hidráulica en México, abril-junio, volumen IX, número 2, p. 64.

Jorge Adán Miller García, peón en la referida obra y vecino del pueblo de Buenavista, expresó años después la siguiente frase: «Con la presa Oviachic nos cortaron el río, la vida y la tierra». ${ }^{95}$ La expresión de Miller García es el reflejo del sentimiento que embargaba a los pobladores de aguas de aguas abajo, que solamente verían fluir las aguas sobre el cauce del río Yaqui cuando desfogara los excedentes la nueva presa. Ahora, el agua sería enviada por el canal Alto para el riego de las tierras, el cual sí lleva agua de manera permanente.

Durante la construcción del embalse, los propietarios de tierras perforaron pozos dentro del aluvión deltaico con el fin de complementar el agua del río durante la estación seca. ${ }^{96}$ Esta práctica la propuso el intendente

95 Murrieta, s.a., 213.

96 West, 1993, 107-108. En una parte de la llanura semidesértica la mitad de las doscientas veinte mil hectáreas proyectadas, «aun cubiertas con matorrales del desierto fueron rápidamente limpiadas con grandes excavadoras», 107. 
gobernador Alejo García Conde en 1813 ante la falta de agua para el riego de las tierras a consecuencia de la irregularidad de las lluvias. ${ }^{97} \mathrm{Al}$ igual que con la presa La Angostura, habría que esperar el llenado del enorme vaso de almacenamiento, lo cual, en palabras del ingeniero Eduardo Cravioto G, era «un problema por no saber con seguridad cuando puede llenarse». ${ }^{98} \mathrm{En}$ octubre de 1958, el vaso de almacenamiento contenía 2.650 millones de $\mathrm{m}^{3}$. Tal volumen era suficiente para atender la demanda de los usuarios ubicados en una de las zonas más importantes de producción agrícola en el país.

\section{La presa Mocúzari o Adolfo Ruiz Cortines, 1952-1957}

El candidato presidencial del Partido Revolucionario Institucional, Adolfo Ruiz Cortines, anunció en la ciudad de Hermosillo, Sonora, una acción de su futuro gobierno: la construcción de la presa en el sitio llamado Mocúzari (río Mayo). La obra iba a permitir el uso de las aguas de manera controlada, la apertura de veinte mil hectáreas al cultivo y mejorar las sesenta mil que estaban bajo riego deficiente..$^{99}$ Cuando el candidato presidencial estuvo en Navojoa, Sonora, los asistentes al evento político lo recibieron con lonas que tenían el siguiente mensaje «pedimos la construcción de la presa del río Mayo». El ingeniero Benito Bernal, apoyó la demanda en su alocución ante Ruiz Cortines. Por su parte, el ingeniero Juan de Dios Bojórquez, a nombre del candidato, dijo que «la presa sobre el río Mayo sería una de las principales obras que consideraría el candidato si el voto público lo lleva al triunfo». ${ }^{100}$ En las elecciones presidenciales que se celebraron el 6 de julio de 1952, resultó vencedor Adolfo Ruiz Cortines. A partir de ello, la promesa de construir una presa de almacenamiento sobre el río Mayo podría materializarse. En la edición del periódico hermosillense El Imparcial, el 11 de septiembre de dicho año, se publicó la siguiente nota: «Es muy probable que el mes entrante empiecen las obras de construcción de la presa del Mocúzari, la cual permitirá el riego de una importante cantidad

97 Informe sobre las proporciones naturales y políticas de los territorios de las provincias de Sonora y Sinaloa de 14 de agosto de 1813, BNM, Archivo Franciscano, 37, exp. 37/838.1.

98 Oficio del ingeniero Eduardo Cravioto G., director de Hidrología al Subsecretario, México, D.F., 28 de junio de 1958, AHA, Aguas Nacionales, 1, caja 3890, exp. 62776, f. 2.

99 «Discurso del candidato Adolfo Ruiz Cortines en Hermosillo», El Imparcial, Hermosillo, Sonora, 1 de diciembre de 1951, 1. El río Mayo tiene su origen en el estado de Chihuahua.

100 «Discurso del ingeniero Juan de Dios Bojórquez en Navojoa», El Imparcial, Hermosillo, Sonora, 6 de diciembre de $1951,1$. 
de hectáreas de magníficas tierras que no alcanza a mojar el río Mayo sino cuando se desborda». ${ }^{101}$

Los estudios para controlar el régimen del río Mayo datan del año de 1923. El sitio que se eligió fue el llamado Los Mezcales, situado a cuarenta kilómetros aguas arriba de la ciudad de Navojoa. ${ }^{102}$ Los consultores Quinton, Code \& Hill en 1926 propusieron construir la presa en el sitio Mocúzari, aguas arriba de Los Mezcales. ${ }^{103} \mathrm{Al}$ año siguiente, el ingeniero consultor J. B. Bond eligió el sitio llamado Camoa, aguas debajo de Mocúzari, para la construcción de un almacenamiento para el aprovechamiento de las aguas del río Mayo. ${ }^{104}$ El ingeniero Félix Payno Taylor presentó el anteproyecto de la presa de almacenamiento sobre el río Mayo en el Mocúzari. Las razones que se esgrimieron a favor de dicho sitio en lugar de Camoa, fueron las siguientes: el almacenamiento sería de 850 millones de metros cúbicos, el costo de la cortina sería de 88.296.000 pesos y el área a irrigar alcanzaría las 60.000 hectáreas a un precio de 1.480 pesos por hectárea. En cambio, construir la presa de almacenamiento en Camoa equivalía a disminuir la capacidad de almacenamiento a 550 millones de metros cúbicos, el monto de la cortina sería de 70.856.000 pesos y el área a irrigar alcanzaría 47.100 hectáreas a un costo de 1.500 pesos por hectárea. ${ }^{105}$ La obra contaría con boquilla, tres puertos, cortina, diques, sección vertedora, obra de toma y obra de desvío. El puerto número uno se edificaría en la margen derecha de la boquilla. Los puertos números dos y tres se construirían en la margen izquierda. En el puerto tres se ubicaría el vertedor para aprovechar la mayor longitud de la cresta vertedora con un mínimo de excavación. La obra de toma se localizaría en la margen derecha. Además de un túnel de seis metros de diámetro y un tramo de doscientos veinte metros de tubería de acero.

La convocatoria de licitación de la obra la expidió la SRH. Después de la revisión de las propuestas presentadas por las empresas concursantes, se declaró ganadora a la empresa estadounidense Morrison Knudsen. La modificación del medio que trajeron consigo los trabajos fue justificada por el presidente Adolfo Ruíz Cortines con las siguientes palabras: «Todos sabemos que la naturaleza negó a México uno de sus dones más preciados:

101 «Se podría construir la presa Mocúzari», El Imparcial, Hermosillo, Sonora, 11 de septiembre de 1952, 1 .

102 «Presa Mocúzari», 1957, 9.

103 Bond, J. B., 1929, 216, 220-221.

104 «Presa Mocúzari», 1957, 9.

105 Anteproyecto de la presa Mocúzari presentado por el ingeniero Félix Payno Taylor, México, D.F., 10 de octubre de 1952, AHA, Consultivo Técnico, 1, caja 344, exp. 2905, f. 25-26. 
abundantes tierras de riego. De la mayor o menor cantidad de lluvias registradas en la República depende el volumen de producción agrícola». ${ }^{106} \mathrm{Si}$ la naturaleza fue mezquina con los mexicanos, el gobierno federal estaba dispuesto a resarcir esa carencia con obras hidráulicas de gran envergadura, las cuales eran uno de los pilares de la política de irrigación del Estado mexicano, para el avance de la agricultura bajo riego y, con ello, la frontera agrícola en el valle del Mayo.

\section{FIGURA 6}

\section{PLANO DE LA PRESA MOCÚZARI}

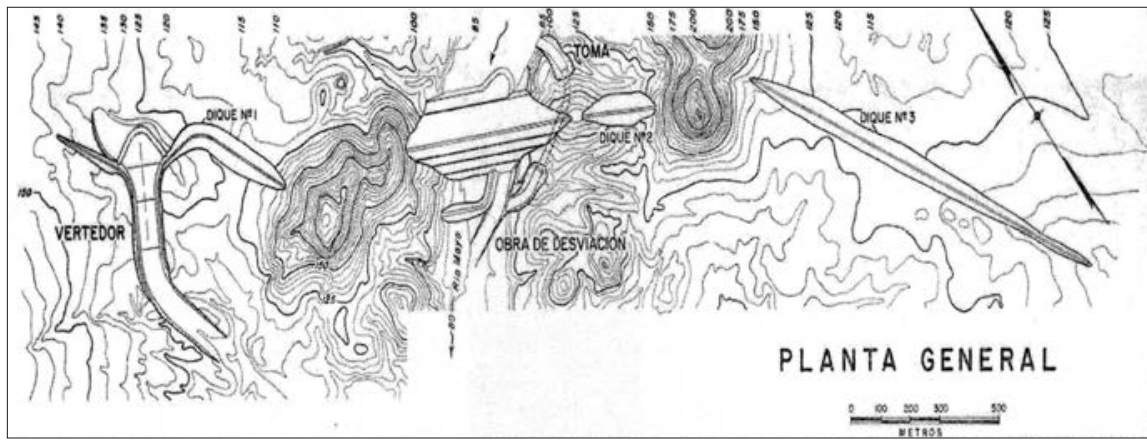

Fuente: Ingeniería Hidráulica de México, octubre-diciembre, XI, 4, 1957, 14.

Desde la óptica presidencial, la necesidad de construir obras hidráulicas en México «se manifiesta, ahora más que nunca, por la sequía que padecemos y que penosamente parece prolongarse. Mientras México siga sujeto en su economía a la temporalidad de las lluvias ningún progreso integral podrá alcanzar». ${ }^{107}$ Para superar tal situación, el gobierno federal llevaba a cabo obras de gran irrigación en veintisiete entidades federativas. Una de ellas fue la presa Mocúzari en el estado de Sonora. Se esperaba irrigar con sus aguas setenta mil hectáreas. ${ }^{108}$ Cabe decir que en la práctica de la agricultura comercial se utilizaban fertilizantes e insecticidas. ${ }^{109}$ La construcción de la citada presa no estuvo exenta de problemas. Los

106 Los Presidentes de México..., 1966, 533.

107 Ibidem, 535.

108 Ibidem, 559.

109 Ibidem, 586. 


\section{FIGURA 7}

\section{OBRAS DE EXCEDENCIAS Y DIQUE NÚMERO 1}

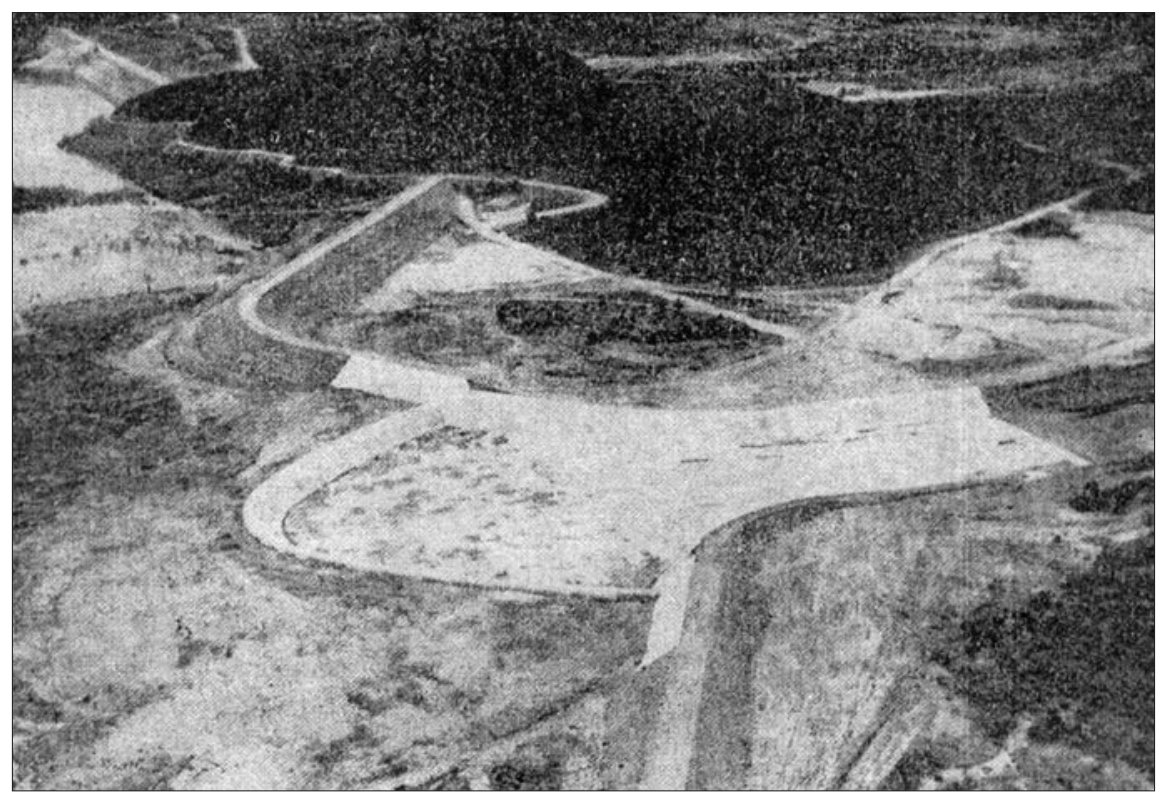

Fuente: Ingeniería Hidráulica de México, octubre-diciembre, XI, 4, 1957, 13.

trabajadores protestaron porque la constructora Morrison Knudsen no se les había otorgado el $10 \%$ de aumento salarial que había ordenado el presidente de la República. La respuesta de la empresa con el aval del gobierno del Estado fue «que el señor Presidente no tiene facultad para legislar y por lo mismo no pudo hacerlo en materia de salarios; el $10 \%$ de aumento que se menciona no fue ordenado, sino simplemente fue sugerido». ${ }^{110}$

El fin de los trabajos de la presa Mocúzari fue registrado por el presidente Adolfo Ruiz Cortines en su informe presentado ante el Congreso de la Unión el 1 de septiembre de 1955. ${ }^{111}$ Los beneficios de la presa Mocúzari, según la Jefatura de Irrigación y Control de Ríos de la SRH, fueron el desarrollo agrícola y económico del sur del estado de Sonora, al ampliar la

110 «La constructora Morrison Knudsen no paga aumento salarial», El Pueblo, Hermosillo, Sonora, 2 de diciembre de 1954, 1.

111 Los Presidentes de México..., 1966, 587. 
frontera agrícola a setenta mil hectáreas, con el desmonte de la vegetación originaria, con lo cual, se superaron las treinta y cinco mil que se regaban de manera precaria por el sistema de riego por inundación — sistema amigable con el medio-; diversificación de la agricultura; protección de la población contra las inundaciones y recreo. ${ }^{12}$ De esta manera, la agricultura de riego es un paisaje continuo desde el río Yaqui hasta el río Mayo. Los dos deltas forman la mayor área agrícola a lo largo de la costa oeste de México. Desde la década de los años sesenta del siglo pasado, en ambos valles hay evidencias de salinidad en los suelos debido a la aplicación excesiva del agua en los campos. ${ }^{113}$ El llenado del vaso de almacenamiento también tardó años. Los que resintieron la falta de agua fueron los algodoneros que tenían bajo cultivo dieciséis mil hectáreas. ${ }^{114}$ Los ejidatarios estaban a la espera de la dotación de aguas por parte del presidente de la República mexicana.

\section{A manera de conclusión}

Por el recorrido realizado, queda clara la intervención del Estado mexicano en el ámbito de la construcción de las grandes presas de almacenamiento. En el caso de la presa La Angostura lo hizo en su papel de constructor asignado en la Ley sobre Irrigación con Aguas Federales de 4 de enero de 1926. En las otras dos, asumió el papel de contratista y supervisor de los trabajos de las empresas constructoras ganadoras de los concursos de licitación. Las inversiones del gobierno federal en la materia de obras hidráulicas fueron millonarias por la importancia que le dieron los encargados del poder ejecutivo federal a la agricultura, como punta de lanza para encauzar la economía mexicana. Además, las grandes presas de almacenamiento a través de la generación de energía eléctrica serían detonantes de la industria. La idea del progreso entendido como una marcha hacia adelante fue lo que delineó la política hidráulica del Estado mexicano.

La prioridad de los presidentes mexicanos, en el periodo bajo estudio, fue mitigar la condición natural de la escasez de las lluvias de verano e invierno, a través de almacenar y controlar las aguas de las corrientes

112 «Presa Mocúzari», 1957, 20. El riego por inundación se utilizaba desde finales del siglo XIX en el valle del Mayo.

113 West, 1993, 108.

114 «La presa Mocúzari no se ha llenado», El Pueblo, Hermosillo, Sonora, 16 de julio de $1957,1$. 
superficiales, en beneficio de los productores agrícolas por varios años, al margen de las vicisitudes climáticas. Los gobiernos federales debían de cumplir con su compromiso de otorgarles el recurso agua a sus concesionarios de aguas y a los nuevos usuarios con la ampliación de la frontera agrícola, para ello utilizaron la tecnología como ariete en la modificación del relieve montañoso de una parte de la Sierra Madre Occidental. La idea que prevaleció entre los presidentes de México y los ingenieros de la CNI y $\mathrm{SRH}$, fue la de dominar a la naturaleza y por ende, a los ríos impetuosos por medio de las grandes presas de almacenamiento, sin reparar en los impactos negativos al medio en el periodo bajo estudio y que hoy tienen expresiones concretas en los campos agrícolas, no sólo de Sonora sino también en otras partes de la República mexicana.

Recibido el 16 de noviembre de 2017 Segunda versión el 19 de febrero de 2018

Tercera versión el 7 de marzo de 2018 Aceptado el 12 de abril de 2018

\section{Referencias bibliográficas}

Aboites Aguilar, Luis, El agua de la Nación. Una historia política de México (1888-1946), México, CIESAS, 1998.

«Acuerdo previniendo que se entrega a la Compañía Constructora Richardson, S. A., la presa de La Angostura, Sonora», Diario Oficial de la Federación, CXXXIV, 45, México, 24 de octubre de 1942, 11-12.

Anguiano Martínez, José Ángel, «La región citrícola en las primeras décadas del siglo XX. Transacciones de tierras y agua y otros datos», en Cerutti, Mario (ed.), Agua, tierra y capital en el noreste de México. La región citrícola de Nuevo León (1850-1940), Monterrey, Universidad Autónoma de Nuevo León, 1991, 229-247.

Ávila Quijas, Omar et al., (coords.), Negociaciones, acuerdos y conflictos en México, siglos XIX y XX. Agua y tierra, México, El Colegio de Michoacán, CIESAS, Universidad Autónoma de Aguascalientes, 2009.

Baroni, Ariane, Colonización del suelo y propiedad: los efectos del liberalismo en Ures, Sonora (1770-1910), México, Universidad de Sonora, 2010.

Benassini, Oscar, «Región del Noroeste de México. Estudio general de gran visión del aprovechamiento de los recursos hidráulicos», Ingeniería Hidráulica en México, 8, 2, México, abril-junio, 1954, 9-25.

Birrichaga Gardida, Diana, «Las empresas de agua potable en México (18871930)» en Suárez Cortez, Blanca Estela (coord.), Historia de los usos sociales 
del agua en México. Oligarquías, empresas y ayuntamientos (1840-1940), México, Comisión Nacional del Agua, CIESAS, IMTA, 1998, 183-225.

Bojórquez Jusaino, María del Carmen, El agua en Hermosillo, 1744-1850. Una historia de usos sociales y conflictos, tesis de maestría en Ciencias Sociales, El Colegio de Sonora, 2006.

Bond, J. B., «Proyecto del río Yaqui. Informe rendido por el ingeniero J. B. Bond en el año 1929», Irrigación en México, X, 4, México, abril, 1935a, 203-230.

Bond, J. B., «Proyecto del río Yaqui. Informe rendido por el ingeniero J. B. Bond en el año 1929», Irrigación en México, X, 5, México, mayo, 1935b, 274-305.

Bond, J. B., «Proyecto del río Yaqui. Informe rendido por el ingeniero J. B. Bond en el año 1929», Irrigación en México, XI, 1 y 2, México, julio y agosto, 1935c, 3-54.

Camacho Pichardo, Gloria, «Proyectos hidráulicos en las lagunas del Alto Lerma (1880-1942», en Suárez Cortez, Blanca Estela (coord.), Historia de los usos sociales del agua en México. Oligarquías, empresas y ayuntamientos (18401940), México, Comisión Nacional del Agua, CIESAS, IMTA, 1998, 229-271.

Castañeda González, Rocío, Irrigación y reforma agraria: las comunidades de riego del valle de Santa Rosalía, Chihuahua 1920-1950, México, Comisión Nacional del Agua, CIESAS, 1995.

Castañeda González, Rocío, «Esfuerzos públicos y privados para el abasto de agua a Toluca (1862-1910)», en Suárez Cortez, Blanca Estela (coord.), Historia de los usos sociales del agua en México. Oligarquías, empresas y ayuntamientos (1840-1940), México, Comisión Nacional del Agua, CIESAS, IMTA, 1998, 107-179.

Cerutti, Mario, Agua, tierra y capital en el noreste de México. La región citrícola de Nuevo León (1850-1940), Monterrey, Universidad Autónoma de Nuevo León, 1991.

Durán, Juan Manuel; Sánchez, Martin y Escobar, Antonio, El agua en la historia de México, México, Universidad de Guadalajara, El Colegio de Michoacán, 2005.

Elías Calles, Plutarco, Pensamiento político y social. Antología (1913-1936), México, Instituto de Estudios Históricos de la Revolución Mexicana, Fideicomiso Archivos Plutarco Elías Calles y Fernando Torreblanca, Fondo de Cultura Económica, 1988.

Escobar Ohmstede, Antonio; Sánchez Rodríguez, Martín y Gutiérrez Rivas, Ana María (coords.), «Manejo del agua en México. Bosquejo de la evolución institucional federal 1926-2008», en Comisión Nacional del Agua, Semblanza histórica del Agua en México, México, Secretaría de Medio Ambiente y Recursos Naturales, 2009, 61-82.

Fabila, Manuel, Cinco siglos de legislación agraria 1493-1940, México, Secretaría de la Reforma Agraria, Centro de Estudios Históricos del Agrarismo en México, 1981. 
«Fabricación de cemento Portland de bajo calor fraguado, en Hermosillo, Sonora», Irrigación en México, 1, México, enero-febrero, 1938, 39-49.

Gayol, Roberto, Dos problemas de vital importancia para la colonización y el desarrollo de la irrigación. Estudios preliminares, México, IMTA, CIESAS, 1994 [1. a ed. 1906].

Gómez Pérez, Francisco, «La irrigación en México», Irrigación en México, XX, 3, México, mayo-junio, 1940, 5-18.

Herrera y Laso, José, Apuntes sobre irrigación. Notas sobre su organización económica en el extranjero y el país, México, IMTA, CIESAS, 1994 [1. a ed. 1919].

Jiménez L., César, «La contribución de la Comisión Nacional de Irrigación al adelanto de la irrigación en México», Irrigación en México, 15, 1, México, enero-febrero, 1937, 3-8.

Kroeber, Clifton B., El hombre, la tierra y el agua. Las políticas en torno a la irrigación en la agricultura de México, 1885-1911, México, IMTA, CIESAS, 1994.

«La política de irrigación del gobierno federal», Irrigación en México, 2, México, junio, 1930, 5-14.

«Las obras de la Comisión Nacional de Irrigación», Irrigación en México, XXI, 3, México, noviembre-diciembre, 1940, 21-158.

Leff, Enrique, Saber Ambiental. Sustentabilidad, racionalidad, complejidad, poder, México, PNUMA, Centro de Investigaciones Interdisciplinarias en Ciencias y Humanidades-UNAM, Siglo Veintiuno Editores, 2013.

«Ley sobre Irrigación con Aguas Federales», Diario Oficial de la Federación, XXXIV, 7, México, 9 de enero de 1926, 99-101.

Lorenzana Durán, Gustavo, Política agraria y movimientos campesinos en los valles del Yaqui y Mayo (1915-1934), Hermosillo, Instituto de Investigaciones Históricas-UNISON, 1991, 72.

Lorenzana Durán, Gustavo, Tierra y agua: una historia política de los valles del Mayo y Yaqui (1934-1940), Hermosillo, Universidad de Sonora, 2006.

Los Presidentes de México ante la Nación. Informes, Manifiestos y Documentos de 1821 a 1966, México, Imprenta Cámara de Diputados, 1966, 971.

Mentz von Brígida y Pérez López, R. Marcela (Comps.), Manantiales, ríos, pueblos y haciendas. Dos documentos sobre conflictos por aguas en Oaxtepec y en el valle de Cuernavaca (1795-1807), México, IMTA, CIESAS, 1998.

Moreno Vázquez, José Luis, Por abajo del agua. Sobreexplotación y agotamiento del acuífero de la Costa de Hermosillo, 1945-2005, México, El Colegio de Sonora, 2006.

Murrieta Mayo, Graf, Ma. Eugenia, Por el milagro de aferrarse. Tierra y vecindad en el Valle del Yaqui, Hermosillo, El Colegio de Sonora, Instituto Tecnológico de Sonora, Instituto Sonorense de Cultura, s. a.

«Nuevas orientaciones de la Comisión Nacional de Irrigación», Irrigación en México, VIII, 1, México, enero, 1934, 3-4. 
Olvera Sandoval, José Antonio, «El valle del Pilón: riego, producción e impactos socioeconómicos (1880-1910)», en Cerutti, Mario (ed.), Agua, tierra y capital en el noreste de México. La región citrícola de Nuevo León (1850-1940), Monterrey, Universidad Autónoma de Nuevo León, 1991, 133-181.

Orive Alba, Adolfo, «Proyecto de programa de irrigación para el sexenio 19411946», Irrigación en México, 23, 1, México, enero-febrero, 1942, 5-14.

Ortega, Juan, «Influencia de las obras de irrigación en la Economía Nacional», Irrigación en México, XVIII, 2, México, septiembre-octubre, 1938, 3-12.

Padilla Calderón, Esther, Agua, poder y escasez. La construcción social de un territorio en un ejido sonorense, 1938-1955, México, El Colegio de México, 2012.

Padilla Calderón, Esther, «Los yaquis y las crecientes del río. Una historia del control hidráulico del río Yaqui», Culturales, 5, 2, Mexicali, 2017, 67-106.

«Presa Álvaro Obregón (El Oviáchic)», Presas de México, 1982-1994, vol. 1, México, Comisión Nacional del Agua, SEMARNAP, s.a., 27-35.

«Presa Mocúzari», Ingeniería Hidráulica en México, XI, 4, México, octubrediciembre, 1957, 9-20.

«Programa sexenal», Irrigación en México, 23, 1, México, enero-febrero, 1942, $15-21$.

Ríos Figueroa, Irene, Colonia Morelos. Un ejemplo de ética mormona junto al río Bavispe (1900-1912), México, El Colegio de Sonora, Sindicato Nacional de Trabajadores de la Educación Sección 54, 2012.

Rodríguez Román, Rocío, «Legislación sobre el agua y conflictos intermunicipales en el siglo XIX», en Cerutti, Mario (ed.), Agua, tierra y capital en el noreste de México. La región citrícola de Nuevo León (1850-1940), Monterrey, Universidad Autónoma de Nuevo León, 1991, 99-132.

Samaniego López, Marco Antonio, Ríos internacionales entre México y Estados Unidos. Los tratados de 1906 y 1944, México, El Colegio de México, Universidad Autónoma de Baja California, 2006.

Segundo Plan Sexenal, 1941-1946, México, Partido de la Revolución Mexicana, s. a.

Sieglin, Verónica, «Agua, acumulación de capital y burguesía en la región citrícola. 1910-1934», en Cerutti, Mario (ed.), Agua, tierra y capital en el noreste de México. La región citrícola de Nuevo León (1850-1940), Monterrey, Universidad Autónoma de Nuevo León, 1991, 15-98.

«Sistemas de riego», Irrigación en México, 15, 1-6, México, julio-diciembre, 1937, 17-120.

Suárez Cortez, Blanca Estela, «Poder oligárquico y usos del agua: Querétaro en el siglo XIX (1838-1880)», en Suárez Cortez, Blanca Estela (coord.), Historia de los usos sociales del agua en México. Oligarquías, empresas y ayuntamientos (1840-1940), México, Comisión Nacional del Agua, CIESAS, IMTA, 1998, 17-103. 
Sterling, Evans, «La angustia de la Angostura: consecuencias socioambientales por la construcción de presas en Sonora», Signos Históricos, 16, México, julio-diciembre, 2006, 46-78.

Velasco, Luis Alfonso, Geografía y estadística de la República mexicana, México, Oficina Tipográfica de la Secretaría de Fomento, 1893.

West, Robert C., Sonora. Its Geographical Personality, Austin, University of Texas, 1993.

White, Stephen S. «The Vegetation and Flora of the Region of the Rio de Bavispe in Northeastern Sonora, México», Lloydia. A Quarterly Journal of Biological Science, 11, 4, Cincinnati, diciembre, 1948, 229-302.

Wolfe, Mikael D., Watering the Revolution. An Enviromental and Technological History of Agrarian Reform in Mexico, Durham, Duke University Press, 2017.

Zebadúa, María, «La lucha por la tierra en la región citrícola: cuatro ejidos», en Cerutti, Mario (ed.), Agua, tierra y capital en el noreste de México. La región citrícola de Nuevo León (1850-1940), Monterrey, Universidad Autónoma de Nuevo León, 1991, 183-228.

Zúñiga, Ignacio, Rápida ojeada al Estado de Sonora, México, impreso por Juan Ojeda, 1835. 